\title{
Preface to the second edition
}

Every piece of historical writing has a theoretical basis on which evidence is selected, filtered, and understood. This statement is as true of scientific empiricism as it is of poststructuralism, although the theory is more likely to be explicit in the latter case. As Peter Loewenberg said: 'Each historian and each age redefines categories of evidence in the light of its needs, sensibilities, and perceptions. The value of any conceptual framework is what new combination of data or inferences from the data it may contribute to the historian's ability to interpret documents and the other raw material of history." In our view, this is one of the enduring strengths of the historical profession, and one of the pleasures of working as a historian.

The original idea for this book developed from an introductory History and Theory course we taught together at the University of Waikato in New Zealand. We wanted to introduce students to the theories behind different kinds of historical writing in order that they might read more critically and reflect on their own historical practice. Students are usually well trained in methodology, but less attention is paid to the theories and concepts underlying historical analyses and arguments. History, along with other academic subjects in the Humanities and Social Sciences, is becoming increasingly interdisciplinary. Historians have begged or borrowed concepts and theories from many other disciplines, leading to an enriched debate around the course of human history, and the implications for both present and future.

We have tried to make this book as straightforward as possible, while pointing to more complex debates in both the introductions and brief additional reading lists at the end of each chapter. The references will also assist you to find further journal articles, chapters, and books. In considering the structure of this reader, we decided to limit ourselves to those schools of historical thought which have had the greatest influence on the historical profession. This was in part due to the restrictions of length necessary in a book designed as a university text, and partly in accordance 
with our belief that these schools were of most relevance to contemporary students. The applied readings were chosen to represent historical writing covering a range of chronological periods and geographical areas. Any stylistic discrepancies/errors in the selected excerpts have been retained, other than occasional very obvious typographical errors which have been silently corrected.

In the spirit of contemporary developments in history and theory, we should also briefly introduce ourselves. Anna Green was born in England, and educated in England, Canada, and New Zealand. She has taught theory and history in New Zealand and England at undergraduate and postgraduate level since the mid-1990s, and her interests lie in the twentieth century, 'history from below', and memory research. Kathleen Troup was born and educated in Australia, and specialized in medieval history with a particular interest in the Annales and social history. After teaching history at tertiary level for over a decade she qualified as a psychologist and psychoanalytic psychotherapist, and brings that expertise to the chapters on psychoanalysis and the emotions.

Many friends and colleagues have discussed our work with us and have thereby lightened the burden of writing. For the second edition we would particularly like to thank the following: Kate de Luna, who commented on the proposal, and our colleagues Cathy Coleborne, Timothy Cooper, Miguel Arnedo-Gomez, Pauline Keating, and Katharine Massam. We have greatly appreciated the support of Emma Brennan and the editorial team at Manchester University Press. Once again we would like to thank our husbands, Jack Vowles and Kai Jensen, for their domestic support, theoretical and editorial comments, and patience with constant historiographical conversations throughout the writing of this book: their presence has been invaluable.

\section{Note}

1 Peter Loewenberg, Decoding the Past: The Psychohistorical Approach (2nd edn, New Brunswick, 1996), p. 15. 